\title{
An Analysis of Sensitivity Tests
}

\author{
Barry T. Neyer
}

Date: March 6, 1992

\section{MOUND}

operated by EG\&G MOUND APPLIED TECHNOLOGIES

P.O. Box 3000, Miamisburg. Ohio $45343-3000$

for the

U. S. DEPARTMENT OF ENERGY

Contract No. DE-AC04-88DP43495 


\section{DISCLAIMER}

This report was prepared as an account of work sponsored by an agency of the United States Government. Neither the United States Government nor any agency Thereof, nor any of their employees, makes any warranty, express or implied, or assumes any legal liability or responsibility for the accuracy, completeness, or usefulness of any information, apparatus, product, or process disclosed, or represents that its use would not infringe privately owned rights. Reference herein to any specific commercial product, process, or service by trade name, trademark, manufacturer, or otherwise does not necessarily constitute or imply its endorsement, recommendation, or favoring by the United States Government or any agency thereof. The views and opinions of authors expressed herein do not necessarily state or reflect those of the United States Government or any agency thereof. 


\section{DISCLAIMER}

Portions of this document may be illegible in electronic image products. Images are produced from the best available original document. 


\section{DISCLAIMER}

Thls report was prepared as an account of work sponsored by an agency of the United States Government Nelther the Unlted States Government nor any agency thereof nor any of their employees makes any warranty express or Implled or assumes any legal llabillty or responsibllity for the accuracy completeness or usefulness of any information apparatus product or process disclosed or represents that its use would not infringe privately owned rights Reference herein to any specific commerclal product process or servlce by trade name trademark manufacturer or otherwise does not necessarily constitute or Imply its endorsement recommendation or favoring by the United States Government or any agency thereof The views and opinions of authors expressed herein do not necessarlly state or reflect those of the United States Government or any agency thereof

This report has been reproduced directly from the best available copy

Avallable to DOE and DOE contractors from

Office of Sclentific and Technical Information

P O Box 62

Oak Ridge TN 37831

Prices available from (615)576-8401 FTS 626-8401

Avallable to the publlc from

National Technical Information Service

U S Department of Commerce

5285 Port Royal Rd

Springfleld VA 22161 
MLM-3736

\title{
An Analysis of Sensitivity Tests
}

\author{
Barry T. Neyer
}

Issued: March 6, 1992

\section{MOUND}

operated by

P.O. Box 3000, Miamisburg, Ohio 45343-3000

for the

U. S. DEPARTMENT OF ENERGY

Contract No. DE-AC04-88DP43495 


\section{Contents}

$\begin{array}{ll}\text { Abstract } & 3\end{array}$

$\begin{array}{lll}1 & \text { Introduction } & 3\end{array}$

2 Estimates of the Parameters $\quad 3$

3 Confidence Interval Estimation $\quad 4$

3.1 Variance Function Method . . . . . . . . . . . . . 5

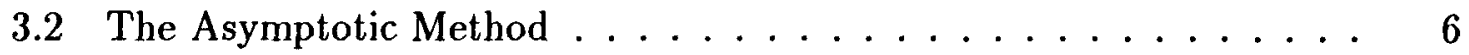

3.3 Simulation Method .................. 8

4 The Likelihood Ratio Test Method $\quad 8$

5 Simulation Results $\quad 10$

6 Conclusions $\quad 16$

$\begin{array}{lr}\text { References } & 20\end{array}$

$\begin{array}{ll}\text { Distribution List } & 22\end{array}$ 


\begin{abstract}
A new method of analyzing sensitivity tests is proposed. It uses the Likelihood Ratio Test to compute regions of arbitrary confidence. It can calculate confidence regions for the parameters of the distribution (e.g., the mean, $\mu$, and the standard deviation, $\sigma$ ) as well as various percentiles. Unlike presently used methods, such as those based on asymptotic analysis, it can analyze the results of all sensitivity tests, and it does not significantly underestimate the size of the confidence regions. The main disadvantage of this method is that it requires much more computation to calculate the confidence regions. However, these calculations can be easily and quickly performed on most computers.
\end{abstract}

\title{
1 Introduction
}

Sensitivity tests are often used to estimate the parameters associated with latent continuous variables which cannot be measured. For example, in testing the sensitivity of explosives to shock, each specimen is assumed to have a critical stress level or threshold. Shocks larger than this level will always detonate the specimen, while smaller shocks will not lead to detonation. Repeated testing of any one sample is not possible since the stress that is not sufficient to cause detonation nevertheless will generally damage the specimen. To measure the parameters of the underlying distribution (e.g., mean threshold, $\mu$, and standard deviation, $\sigma$, of a normal distribution), samples are tested at various stress levels, and the response or lack of response is noted. The experimenter then analyzes the data to provide estimates of the parameters of the population.

A previous paper [1] discussed a number of the sensitivity test designs. This paper will discuss methods of analysis. Section 2 describes the method for estimating the parameters of the distribution. Section 3 describes some of the commonly used methods for estimating confidence intervals. Section 4 proposes a new method of analysis, based on the Likelihood Ratio Test. Unlike previously used methods, this new method can analyze the results of all tests, and does not produce confidence intervals that are biased small. Section 5 presents simulation results.

\section{Estimates of the Parameters}

The analysis of sensitivity tests is more complicated than the analysis of many standard statistical tests since the experimenter does not have any threshold information about the individual elements in the sample (i.e., the experimenter cannot compute a simple average to estimate the mean threshold, $\mu$, because there is nothing to average). The only information is the stress applied to each specimen and the response or lack of response.

A very general method of analyzing these tests is to use the method of Maximum Likelihood. Let $x_{i}$ be the (transformed) stimulus level for the $i$ th test, $n_{i}$ be the number tested at this level, and $p_{i}$ be the proportion of samples that responded. (The responses are often called successes and the non-responses failures.) Let $P\left[\left(x_{i}-\mu\right) / \sigma\right]$ 
be a known distribution function with $\mu$ and $\sigma$ the unknown parameters. (Usually a normal distribution is assumed, but any probability function can be used. Additional parameters might be needed for other distributions.) Define $z_{i}=\left(x_{i}-\mu\right) / \sigma, Q(z)=$ $1-P(z)$, and $q_{i}=1-p_{i}$. The likelihood function, $L(\mu, \sigma)$, is the probability of obtaining the given test results with the specified $\mu$ and $\sigma$. It is given by

$$
L\left(\mu, \sigma \mid x_{i}\right)=\prod_{i}\left(\begin{array}{c}
n_{i} \\
p_{i} n_{i}
\end{array}\right) P\left(z_{i}\right)^{n_{1} p_{i}} Q\left(z_{i}\right)^{n_{i} q_{i}} .
$$

The values, $\hat{\mu}$ and $\hat{\sigma}$, which maximize the likelihood function, are the Maximum Likelihood Estimates (MLE's). It is easier to find the parameters which maximize $\mathcal{L}$, the $\log$ of the likelihood function. Unique MLE's are obtained if the successes and failures overlap; i.e., the smallest success is smaller than the largest failure [2].

There is no guarantee that the MLE's are unbiased. The simulation reported in this work and that of others $[3,4]$ shows that $\hat{\mu}$ is essentially unbiased and $\hat{\sigma}$ is biased low in most cases of practical interest.

It is also possible to estimate other points of the distribution, such as various percentiles. Let $L_{p}$ be the $100 p$ th percentile of the population. Define $z_{p}$ such that $P\left(\mu+z_{p} \sigma\right)=p$. Then

$$
\hat{L}_{p}=\hat{\mu}+z_{p} \hat{\sigma} \text {. }
$$

Thus, Maximum Likelihood Estimates of $\mu$ and $\sigma$ directly yield estimates of $p$.

Most modern analysis methods use the Maximum Likelihood Estimates as estimates of the parameters. However, different analysis techniques were often employed by many researchers before electronic computers became accessible, due to the difficulty of the calculations.

The Probit test [5] was designed to allow easy analysis by plotting the probability of success as a function of stress on normal probability paper. If the data lie on a straight line, the mean and standard deviation can be simply read from the mid point and slope of the line, respectively.

The Bruceton test [6] was designed to allow the experimenter to estimate $\mu$ and $\sigma$ from the data by computing sums of the number of tests conducted at a test level multiplied by the stress levels and their squares. It also produces estimates of the variances of these parameters, based on the asymptotic method discussed in Section 3.2.

Both of these specialized methods give estimates close to the Maximum Likelihood Estimates under favorable conditions.

\section{Confidence Interval Estimation}

Unlike the estimation of the parameters, there are a number of very different methods of estimating the confidence intervals for the parameters. The simulation discussed in Section 5 shows that the variance of both $\hat{\mu}$ and $\hat{\sigma}$ is approximately proportional to $\sigma^{2}$. Since $\sigma^{2}$ is not independently known, the variance function method discussed in Section 3.1, the asymptotic method discussed in Section 3.2, and the simulation 
method discussed in Section 3.3 base their estimates on the Maximum Likelihood Estimate of $\sigma, \hat{\sigma}$. If the successes and failures do not overlap, $\hat{\sigma}=0$, and these methods fail to produce estimates for confidence regions for both $\mu$ and $\sigma$. However, the Likelihood Ratio Test, discussed in Section 4, is able to produce reliable confidence interval estimates in all cases, including this degenerate case.

\subsection{Variance Function Method}

The variance function method of estimating confidence intervals makes the assumption that the variances of both $\hat{\mu}$ and $\hat{\sigma}$ are relatively simple functions of just the sample size and the standard deviation of the population. For example, Langlie [7] states that under certain conditions for the Langlie ("one-shot") method,

$$
\begin{aligned}
& \operatorname{Var} \hat{\mu} \approx 2.5 \sigma^{2} / N \\
& \operatorname{Var} \hat{\sigma} \approx 3.2 \sigma^{2} / N,
\end{aligned}
$$

where $N$ is the sample size. A more recent approximation [8], more consistent with the results of the simulation reported in Section 5, gives larger variances for $\sigma$ when the sample size is larger than 20 :

$$
\operatorname{Var} \hat{\sigma} \approx 1.2 \sigma^{2} / N^{2 / 3} \text {. }
$$

Langlie [8] also established the bias of the estimate of $\sigma$ under the same circumstances. Let $\beta=(\hat{\sigma}-\sigma) / \sigma$ be the relative bias ${ }^{1}$ of the estimate $\hat{\sigma}$. Then

$$
\beta \approx 1.6 / N^{2 / 3} .
$$

For large $N$ the bias goes to zero as expected. Since $\beta^{2} \rightarrow 0$ faster than $\operatorname{Var} \hat{\sigma} \rightarrow 0$, $\hat{\sigma}$ is "essentially unbiased" for large $N$.

To calculate confidence intervals for $\hat{\mu}$, Langlie [7] advocates that "Until such time when a 'small-sample' statistic equivalent to 'Student's $t$ ' statistic is developed for the 'one-shot' method, the large sample approach will be taken by substituting the unbiased standard deviation, $(1+\beta) \hat{\sigma}$, for $\sigma$ in calculating the variance in $\hat{\mu}$ for a given sample size of N." Based on this analysis, the $\alpha$ confidence interval for $\mu$ is given by

$$
\mathrm{CI}_{\alpha}(\mu)=\hat{\mu} \pm \sqrt{\operatorname{Var} \hat{\mu}} z_{(1+\alpha / 2)} .
$$

Similarly, confidence intervals for the percentile $p$ are given by

$$
\mathrm{CI}_{\alpha}(p)=\hat{\mu}+z_{p} \hat{\sigma} \pm \sqrt{\operatorname{Var} \hat{\mu}+z_{p}^{2} \operatorname{Var} \hat{\sigma}} z_{(1+\alpha / 2)} .
$$

Several software programs $[9,10]$ use Equations $3-8$ to estimate confidence intervals for $\mu$ or various values of $p$.

\footnotetext{
${ }^{1}$ The notation in this paper is different from that of Langlie's paper. He defines the Maximum Likelihood Estimates of $\mu$ and $\sigma$ as $\mu_{e}$ and $\sigma_{e}$ respectively, and the bias as $\beta=\sigma_{e} / \sigma$. His "unbiased" $\sigma$ is $\hat{\sigma}=\sigma_{e} / \beta$.
} 
Estimation of confidence intervals for $\sigma$ could similarly be computed, but they often include negative numbers. Langlie [7] recommends a chi-squared method of calculation for all samples less than 50 . The ratio $n \hat{\sigma}(1+\beta) / \sigma$ was assumed to follow a chi-square distribution with $n$ degrees of freedom. Using Equation 4 to estimate the variance of $\hat{\sigma}$ determines the "effective" degrees of freedom for a Langlie test:

$$
n=0.625 N(1+\beta)^{2} .
$$

The confidence limits for $\sigma$ can be calculated by determining the coefficients of the chi-squared distribution at the appropriate confidence. The program ONE_SHOT [10] uses this method to calculate confidence intervals for $\sigma$. It calculates confidence intervals for $\sigma$ based on both Equation 4 and 5. However, this software does not calculate confidence intervals for various percentiles.

The variance function method depends on the validity of the equations used to estimate the variance. Equations 3-5 were obtained from simulating the Langlie test under optimal conditions. The variance is a complicated function of the population, the sample size, and the test design. Thus, new equations must be determined for different tests and for the same tests with different initial assumptions.

The program BRUCETON [11] uses the results of simulation to estimate confidence intervals by functions similar to, but more complicated than, those given by Equations 3-4.

In addition, the detailed simulation described in Section 5 and in other work $[3,4]$ shows that the variance is often worse for a Langlie test than that given by Equations 3 and 5 when the test is not optimized for the population. The Langlie test is most efficient [7] for sample sizes less than 50 when the test limits are chosen as $\mu \pm 4 \sigma$. In this case, Equations 3 and 5 yield estimates of the variance that closely match the results from simulation. However, if the limits chosen are either much wider or narrower, the variance of both $\mu$ and $\sigma$ can be a factor of two or more times that

given by Equations 3 and 5. (For sample sizes on the order of 100 or larger, wider limits are more efficient than those suggested by Langlie.)

One further restriction of these methods is that they do not work if there is no cross-over or overlap of the data. In this case, the estimate of the standard deviation, $\hat{\sigma}$, is zero. Equations 3 and 4 would say that the variance of both $\hat{\mu}$ and $\hat{\sigma}$ would be zero. Thus, no meaningful confidence interval can be constructed in these cases.

\subsection{The Asymptotic Method}

The asymptotic method is used by programs such as ASENT [12] and in the calculations of the variance in the Bruceton method [6]. The Cramér-Rao theorem [13] gives a lower bound of the variance for all unbiased estimates of the distribution. This lower bound approaches the true variance asymptotically. Let $t$ be an unbiased estimator of some function $\tau\left(\theta_{i}\right)$, where the $\theta_{i}$ represent the parameters $\mu$ and $\sigma$. Then the lower bound of the variance of $t$ is given by

$$
\operatorname{Var} t \geq \sum_{i} \sum_{j} \frac{\partial \tau}{\partial \theta_{i}} \frac{\partial \tau}{\partial \theta_{j}} I_{i j}^{-1},
$$


where the information matrix is

$$
\begin{aligned}
\left\{I_{i j}\right\} & =\left\{E\left(\frac{\partial \mathcal{L}}{\partial \theta_{i}} \frac{\partial \mathcal{L}}{\partial \theta_{j}}\right)\right\} \\
& =-\left\{E\left(\frac{\partial^{2} \mathcal{L}}{\partial \theta_{i} \partial \theta_{j}}\right)\right\} .
\end{aligned}
$$

The second form of the information matrix is valid as long as the limits of integration are independent of the parameters [13].

For sensitivity tests, $E\left(p_{i}\right)=P\left(z_{i}\right)$. Let $\theta_{0}=\mu$ and $\theta_{1}=\sigma$ and define

$$
J_{j}\left(z_{i}\right)=P^{\prime 2}\left(z_{i}\right) z_{i}^{j} /\left[P\left(z_{i}\right) Q\left(z_{i}\right) \sigma^{2}\right] .
$$

The information matrix for sensitivity tests has the following elements:

$$
I_{j k}=\sum_{i} n_{i} J_{j+k}\left(z_{i}\right)
$$

They are found by adding the $J_{j}\left(z_{i}\right)$ functions evaluated for each test level.

The asymptotic variance of the MLE's are given by terms in the inverse of the information matrix:

$$
\begin{aligned}
\operatorname{Var} \hat{\mu} & =I_{11} /\left(I_{00} I_{11}-I_{01}^{2}\right) \\
\operatorname{Var} \hat{\sigma} & =I_{00} /\left(I_{00} I_{11}-I_{01}^{2}\right)
\end{aligned}
$$

The asymptotic methods of estimation of the variance of the parameters uses Equations 13-16 with $\hat{\mu}$ and $\hat{\sigma}$ substituted for $\mu$ and $\sigma$ respectively. The confidence intervals are constructed from the variances according to Equations 7 and 8 and a similar equation for $\sigma$.

Equations 7 and 8 can be generalized to compute joint confidence regions for both $\mu$ and $\sigma$. With the same assumptions used to create the confidence intervals for individual parameters, joint confidence regions are bounded by the ellipse given by the equation

$$
\sum_{i j} I_{i j}\left(\hat{\theta}_{i}-\theta_{i}\right)\left(\hat{\theta}_{j}-\theta_{j}\right) \leq \chi_{\alpha}^{2}
$$

where

$$
\alpha=Q\left(\chi_{\alpha}^{2} \mid \nu=2\right)
$$

In spite of the difficulties mentioned in Section 5 , the asymptotic methods of analysis have gained wide acceptance. The main advantage of this method is that the calculations are relatively simple to perform. Another advantage is that the estimates of the variance change with the test design as the simulation variances change. Thus, one procedure can be used to calculate estimates for all test designs. The asymptotic method is the basis of various versions of the ASENT program $[12,14,15,16,17]$, used by the explosive test community.

The Bruceton analysis for the confidence intervals was developed in the 1940's to enable calculating parameters and confidence intervals by computing simple sums. It 
is based on asymptotic analysis, with one further approximation. It calculates limits based on the assumption that the distribution of successes and failures at the various test levels follows the asymptotic distribution. According to Dixon and Mood [6] this analysis is valid only if the sample size is larger than approximately 50 and the step size is between 0.5 and 2.0 times $\sigma$. As long as these conditions are met, then the Bruceton analysis generally yields estimates similar to the ASENT programs.

As in the variance function method described previously, the asymptotic methods cannot provide estimates of the variances or confidence intervals when there is no overlap. Taking the limit of Equation 13 gives

$$
\lim _{\sigma \rightarrow 0} J_{j}\left(z_{i}\right)=0 .
$$

Use of Equations 15 and 16 shows that the asymptotic limits are infinite when the data do not overlap.

\subsection{Simulation Method}

The simulation method is used by some experimenters [4]. A Monte Carlo simulation is used to measure the variance of the parameters of interest. A value is assumed for $\mu$ and $\sigma$, and a test design is selected. The program conducts a sensitivity test using a random number to determine if the specimen would respond at the specified stress level. After the required number of specimens are tested, Maximum Likelihood Estimates for the parameters are computed. The simulation is repeated many times, and the mean and variance of the parameters are computed.

The simulation methods are simple in principle, but require some care in their use. The simulation results are for a given value of $\mu$ and $\sigma$. For many sensitivity test designs, Bruceton and Langlie tests in particular, the variance of the parameters is a complicated function of the parameters, the sample size, and the spacing of the stress levels about $\mu$. Thus, the experimenter must perform a simulation, involving thousands of repetitions, closely matched to the exact experimental conditions. Moreover, since the experimenter does not know the true values of the parameters of the distribution, the MSE's are generally used for the simulation instead of the true parameters. Thus, many simulations with variations of the parameters must be performed to determine reliable estimates of the variation of the parameters. If all the necessary precautions are taken, simulation provides a reliable method of estimating the confidence intervals. However, as in the previous methods, confidence intervals are usually not predicted if there is no overlap of response and non-response

levels. It is possible to determine the range of parameters that would be likely to yield non-overlapping results; however, this approach is rarely taken.

\section{The Likelihood Ratio Test Method}

The Likelihood Ratio Test [13] can be used to estimate confidence intervals for sensitivity tests. It can be used to analyze all tests, even those where there is no overlap. 
Let $L(x \mid \theta)$ be a likelihood function, where $x$ represents the experimental values $\left(x_{i}, n_{i}, p_{i}\right)$ and $\theta$ represents the parameters $\mu$ and $\sigma$. The vector $\theta=\left(\theta_{r}, \theta_{s}\right)$ has $k=r+s$ parameters $(r \geq 1, s \geq 0)$. Confidence regions can be found by testing the hypothesis

$$
H_{0}: \theta_{r}=\theta_{r 0}
$$

against the alternative

$$
H_{1}: \theta_{\mathrm{r}} \neq \theta_{\mathrm{r} 0} .
$$

Let $\hat{\theta}=\left(\hat{\theta}_{r}, \hat{\theta}_{s}\right)$ be the unconditional MLE's and $\hat{\hat{\theta}}=\left(\theta_{r 0}, \hat{\hat{\theta}}_{s}\right)$ be the MLE's given $H_{0}$. The ratio

$$
l=\frac{L\left(x \mid \theta_{r 0}, \hat{\hat{\theta}}_{s}\right)}{L\left(x \mid \hat{\theta}_{r}, \hat{\theta}_{s}\right)}
$$

is an indication of likelihood that $H_{0}$ is true. The closer $l$ is to 1.0 , the more likely it is that $H_{0}$ is true. If asymptotic normality and efficiency of the MLE's are satisfied, then

$$
-2 \ln l \sim \chi_{r}^{2}
$$

for large sample sizes [13].

Equation 23 can only be established asymptotically in general, but is true for all sample sizes for some distributions. For example, in a normal distribution, the Likelihood Ratio Test leads to the "students $t$ " test when testing the mean. The simulation reported in Section 5 shows that $l$ follows the asymptotic distribution well for sample sizes greater than approximately 20 for sensitivity tests.

The calculation of Likelihood Ratio confidence regions is conceptually simple, although the computations themselves are quite complex. For a given $l_{\alpha}$ compute the region

$$
C I_{\alpha}\left(\theta_{r}\right)=\left\{\theta_{r} \mid l_{\alpha}<\frac{L\left(x \mid \theta_{r}, \hat{\hat{\theta}}_{s}\right)}{L\left(x \mid \hat{\theta}_{r}, \hat{\theta}_{s}\right)}\right\} .
$$

Since the MLE parameters are unique when the data overlap [2], this region is composed of all points internal to the boundary defined by Equation 22. (When there is no overlap, the likelihood function is unity for all values of $\mu$ inside the interval between the highest failure and the lowest response when $\sigma=0$. Efficient test designs ensure overlap as the sample size increases. This test can be used, with a slight modification discussed in Section 5, to analyze the results of these tests.)

It is straight forward to compute the confidence ratios, $l_{\alpha}$, for any given $\alpha$ assuming Equation 23 is true. For example, to compute a confidence region for both $\mu$ and $\sigma$ simultaneously, there are two degrees of freedom, and $P[-2 \ln l<a]=\chi^{2}(a \mid \nu=2)=$ $1-e^{-a / 2}$. Letting $\alpha=e^{-a / 2}$ gives $P[l>\alpha]=1-\alpha$. Thus, the joint confidence region of size $\alpha$ for both $\mu$ and $\sigma$ is specified by the confidence ratio

$$
l_{\alpha}=1-\alpha \quad(2 \text { degrees of freedom }) .
$$

Similarly, a confidence region for a single parameter (also called a confidence interval) can be estimated from the confidence ratio

$$
l_{\alpha}=1-2 Q(-2 \ln \alpha) \quad(1 \text { degree of freedom }) .
$$


This technique can estimate confidence intervals for $\mu, \sigma$, or other $100 p$ th percentiles.

The main disadvantage of this technique is that much calculation is needed to compute the confidence intervals. The calculation must use iterative techniques to follow various contours of the likelihood function to determine which combination of parameters gives the smallest and largest values. However, the confidence intervals for all parameters are determined by the same contour. (It can take between one second to several minutes to compute confidence regions on a personal computer.) Several programs $[18,19,20]$ employ this method to calculate confidence intervals.

The Likelihood Ratio Test can also be applied to test if two samples were drawn from the same or different populations. In this case, the ratio of the likelihood function,

$$
l=\frac{L\left(x_{1} \mid \theta_{1}\right) L\left(x_{2} \mid \theta_{2}\right)}{L\left(x_{1} \mid \theta_{t}\right) L\left(x_{2} \mid \theta_{t}\right)}
$$

is an indication of whether the two sets of parameters are the same or different. Since there are two degrees of freedom, Equation 25 holds asymptotically. A ratio of $l$ means that you are $1-l$ confident that the two samples were drawn from different populations. Several programs $[21,22]$ employ this method to test for differences.

\section{Simulation Results}

Simulation was performed to test the ability of the Likelihood Ratio Test to analyze the results of a wide variety of sensitivity tests. The details of the simulation have been described in a previous paper [1] describing a more efficient sensitivity test. Several additions were made to the simulation to accommodate this study.

Simulations were performed for the Bruceton [6], Langlie [7], and Neyer [1] tests when the initial guess of sigma, $\sigma_{\text {guess }}$, was a multiple of the true $\sigma$. After each test, MLE's of the parameters were computed. The variances of these estimates were computed to estimate the efficiency of each test. In addition, two histograms of likelihood ratios were computed. One histogram recorded the ratios of the likelihood function evaluated at the true parameters divided by the likelihood ratio at the MLE's. The second recorded the ratio of the joint likelihood function of two consecutive tests, assuming that they had common $\mu$ and $\sigma$, divided by the product of the likelihood functions with their individual $\mu$ and $\sigma$. Both histograms are cumulative histograms; they graph the fraction of ratios lying below $l$ as a function of $l$.

Sensitivity tests sometimes result in tests with no overlap because of limited sample size or an inefficient test design due to faulty initial estimates of the parameters. Care must be taken when analyzing these experiments. Many researchers have suggested that either these tests be ignored, or additional samples be tested until overlap occurs. However, both of these suggestions cause problems in actual experiments. There is no reason to ignore the results if the data do not overlap, and it is often impossible to increase the sample size if the specimens require much preparation. Thus, realistic simulation must include tests with no overlapping data.

Let $L_{h f}$ denote the level of the highest failure and $L_{l s}$ denote the level of the lowest success. Tests with no overlap are signaled by $L_{h f}<L_{l s}$. In this case the likelihood 
function would be exactly one for any value of $\mu$ chosen between $L_{h f}$ and $L_{l s}$ when $\sigma$ is equal to zero. However, if there is overlap (i.e., $L_{h f}>L_{l s}$ ), or if $L_{h f}=L_{l s}$ then the maximum possible value of the likelihood function is 0.25 . There should be little difference between the confidence regions of three tests, one with $L_{h f}=L_{l s}-\epsilon$, the second with $L_{h f}=L_{l s}$, and the third with $L_{h f}=L_{l s}+\epsilon$, where $\epsilon$ is some small number. Thus the ratios were constructed in two different ways, one using the actual likelihood values, and a second substituting $\mathbf{0 . 2 5}$ for the likelihood function for all tests that did not have overlapping results.
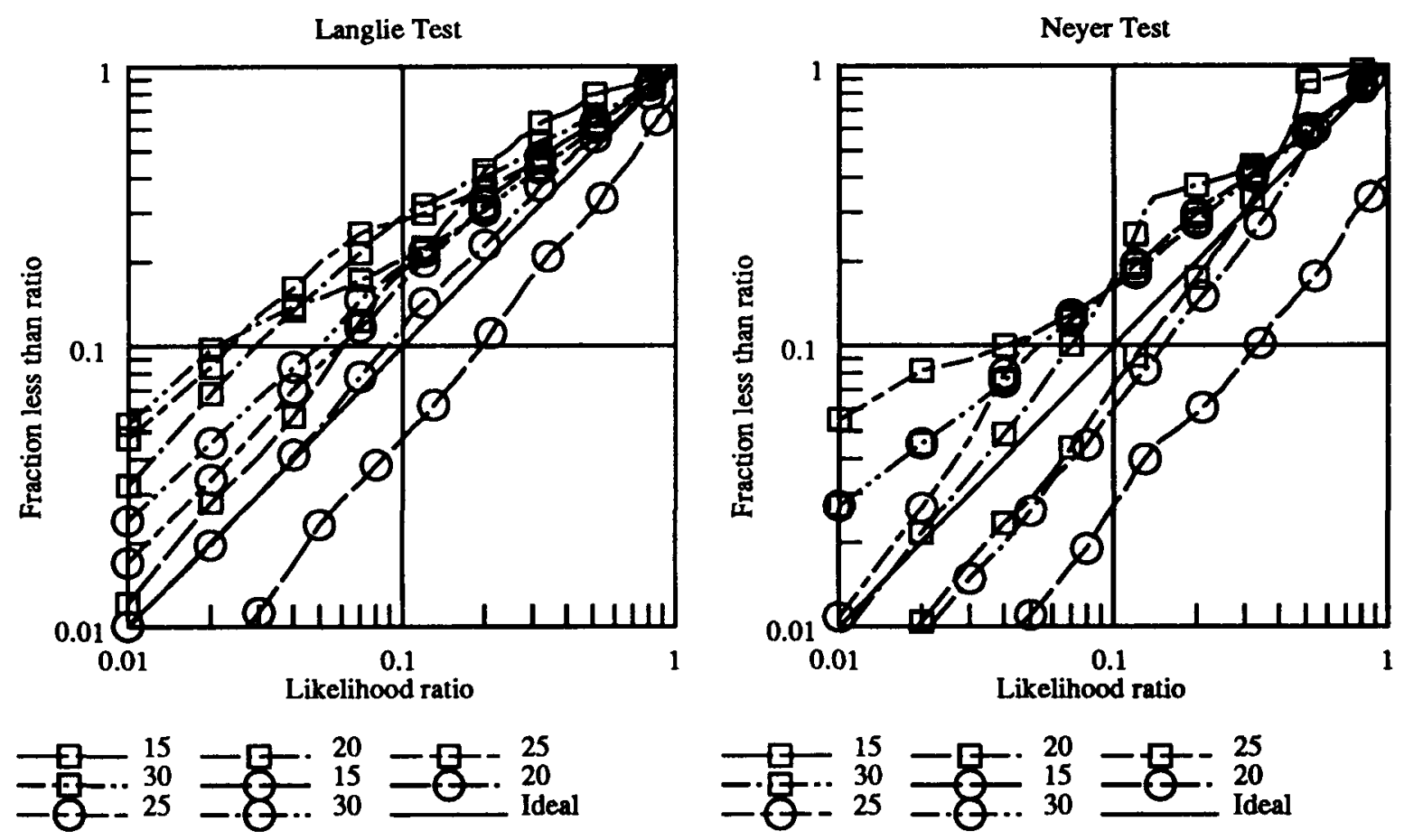

Figure 1: Corrected and Uncorrected Likelihood Ratio Tests. The corrected ratios, shown with circles, are somewhat closer than the uncorrected ratios, shown with squares.

Figure 1 shows the comparison between the corrected and uncorrected ratios for the Langlie and Neyer tests with a variety of sample sizes from 15 to 30 . The curves with squares are uncorrected while the curves with circles are corrected. Since all tests have (the far from optimal) $\sigma_{\text {guess }}=0.1 \sigma$, a significant fraction of the tests yielded results that did not overlap. Inspection of the graphs show that the corrected ratios were somewhat closer on the average to the ideal case (shown by the solid line) than the uncorrected ratios. Since corrected ratios result in more conservative confidence regions, and are stable with respect to small changes in the test level, they were used for the rest of the work. The probability of overlap for efficient test designs increases to unity as the sample size increases. Thus, both the corrected and uncorrected ratios have the same asymptotic form.

Figures 2-4 show the result of the simulations. These figures show the histograms of the ratio of the likelihood function evaluated at the true parameters divided by the maximum likelihood function. Each figure shows the ratios for the seven cases of 
$\mu=\mu_{\text {guess }}, \sigma=(0.1,0.2,0.5,1.0,2.0,5.0$, and 10.0$) \sigma_{\text {guess }}$ for various sample sizes and sensitivity tests. The legend shows the ratio of the population $\sigma$ to the guess used in the design of the test, $\sigma_{\text {guess. }}$. (Previous study [1] has shown that wrong values of $\mu$ generally have little effect on sensitivity tests.) For these ratios, there are two free parameters, $\mu$ and $\sigma$. Thus Equation 25 should hold asymptotically.

As is seen from the figures, even for sample sizes as small as 20 , the ratios are close to the asymptotic value shown as the solid line in the figures, as long as the test is efficient (i.e., $\sigma \approx \sigma_{\text {guess }}$ ). The ratios approach the asymptotic value as the sample size increases. The only exception is when the test design is very inefficient for large samples (i.e., Bruceton tests when $\sigma \ll \sigma_{\text {guess }}$ ). Moderately inefficient tests (i.e., Bruceton and Langlie tests when $\sigma \gg \sigma_{\text {guess }}$ ) approach the asymptotic value, but more slowly than test designs matched to the population. Since the Neyer test is asymptotically efficient regardless of the initial estimates of the parameters [1], it rapidly approaches the asymptotic values when the sample size is reasonable. Since researchers often repeat a sensitivity test if the initial assumptions about the population are far from the truth, the Likelihood Ratio Test can be used to compute confidence regions in most cases.

In evaluating these graphs, it is important to note that the graphs illustrate how the computed confidence regions compare to the actual confidence regions for a variety of tests under different conditions. These graphs give no indication of the size of the confidence regions for the parameters. Thus, they should not be viewed as a measure of how efficiently a given test can measure the parameters of the distribution. The efficiency of these test designs has been reported in previous works $[1,3,7]$.

The same simulation was used to compute histograms of the fraction of time the true parameters were inside the confidence region that was computed by the asymptotic method. (See Section 3.2.) The simulation has shown that the true variance is often larger than the asymptotic variance by a factor of two or more. Thus, the true confidence is often much smaller than that suggested by the asymptotic method. For example, a $99 \%$ confidence region computed by the asymptotic method would fail to contain the true parameters $26 \%$ of the time for a 20 sample Langlie test performed under ideal conditions! Figure 5 shows that when sample sizes are even as large as 100, with Bruceton, Langlie, and Neyer tests performed under ideal conditions, the asymptotic method significantly underestimates the confidence regions when the confidence is larger than $90 \%$. Thus, reliance upon the asymptotic method could lead to much false confidence in the data.

Similarly, the histograms in Figures $6-8$ are a measure of the relationship between the confidence $\alpha$ and the likelihood ratio, $l$. These histograms used the same three tests and same ratios of $\sigma$ to $\sigma_{\text {guess }}$ as used in Figures 2-4. The histograms show the ratio of the product of two likelihood functions evaluated at their joint MLE's to the product of the likelihood functions evaluated at their individual MLE's. Thus, they can be used to test whether the two samples were drawn from the same or different populations.

Since there are two extra parameters in the denominator ( $\mu_{t}$ and $\sigma_{t}$ for the numerator and $\mu_{1}, \sigma_{1}, \mu_{2}$, and $\sigma_{2}$ in the denominator) Equation 25 should hold asymptotically. As is seen from the figures, the asymptotic relationship is reasonable, even 
Sample Size: 20

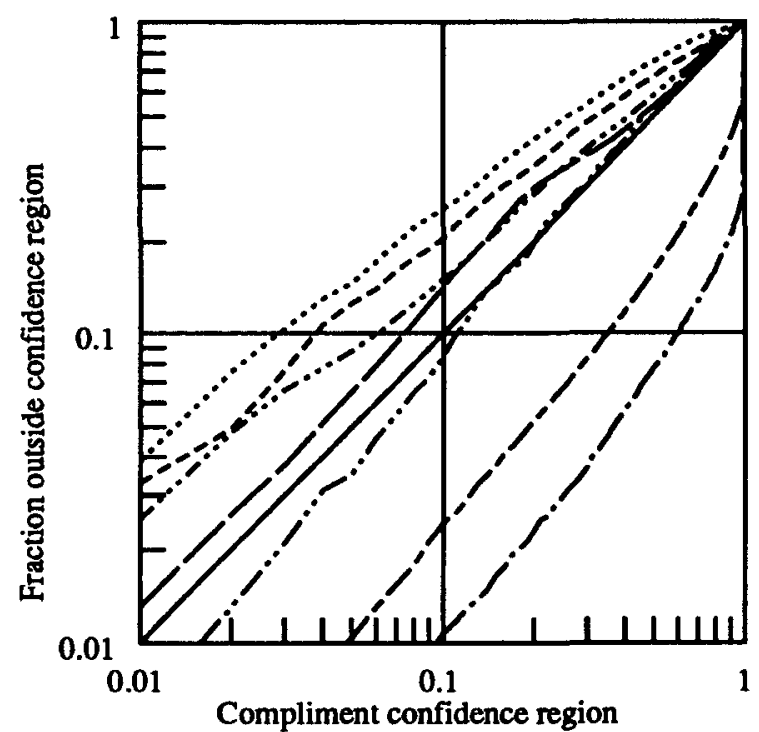

Compliment confidence region
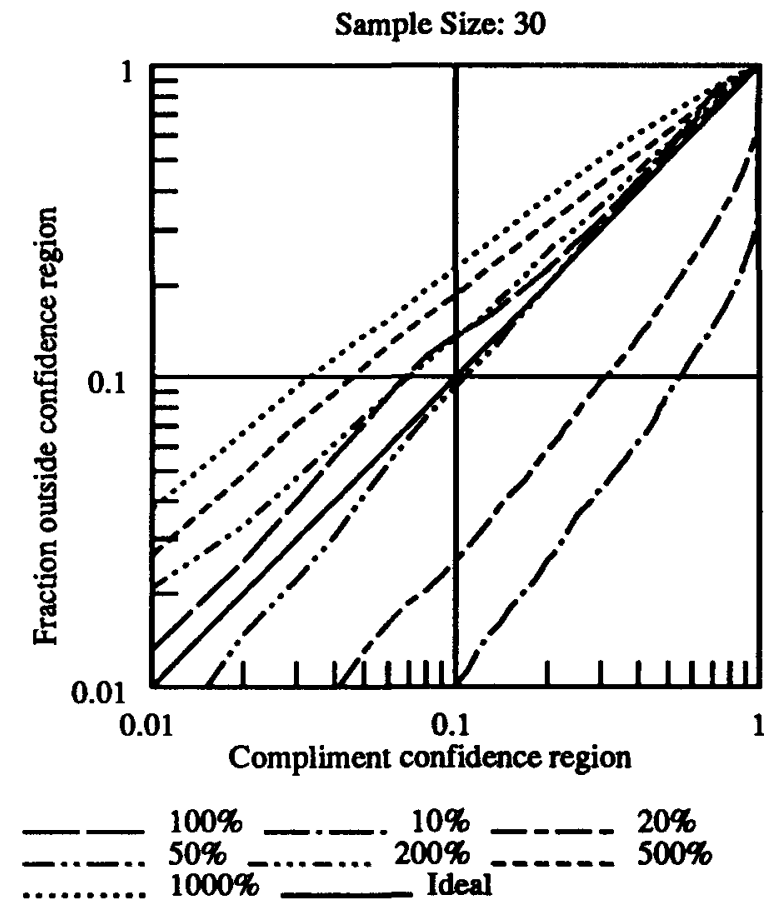

Sample Size: 100
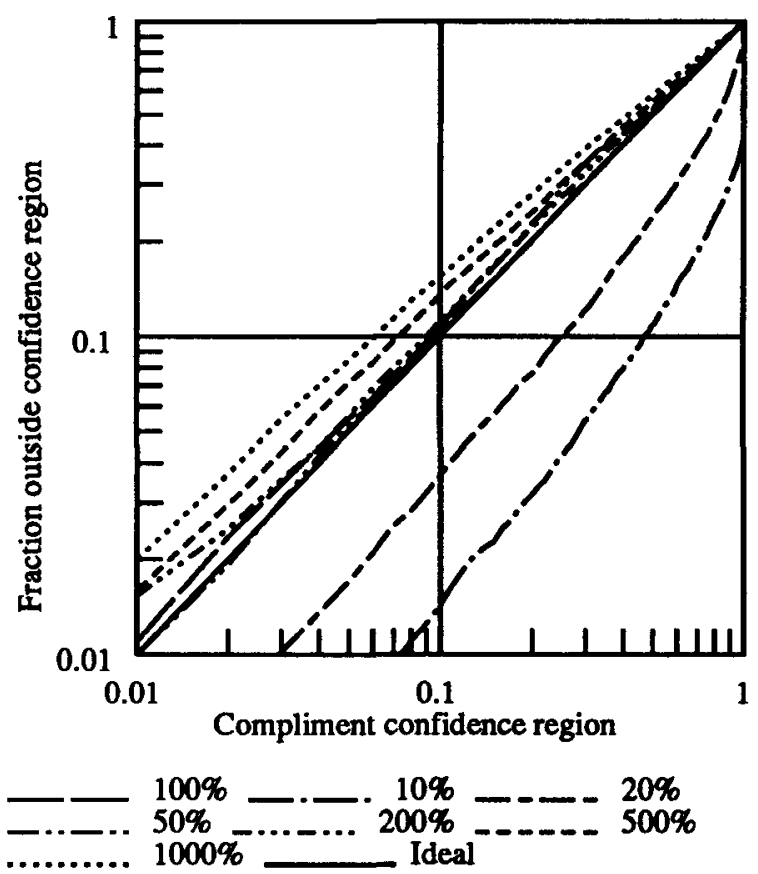

Figure 2: Cumulative likelihood ratio distribution for the Bruceton test. 
Sample Size: 20

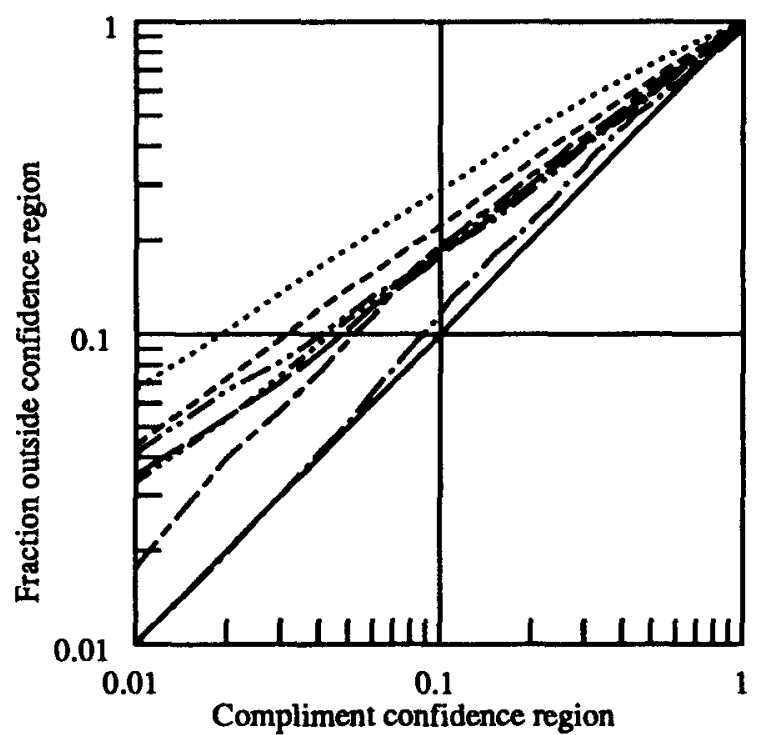

Compliment confidence region
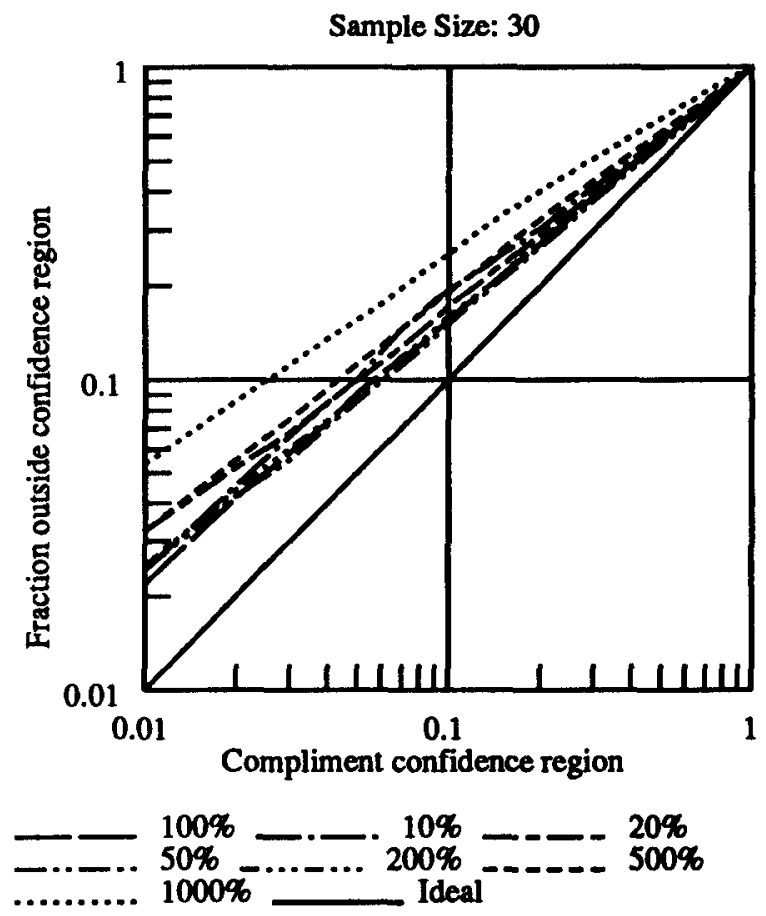

Sample Size: 100
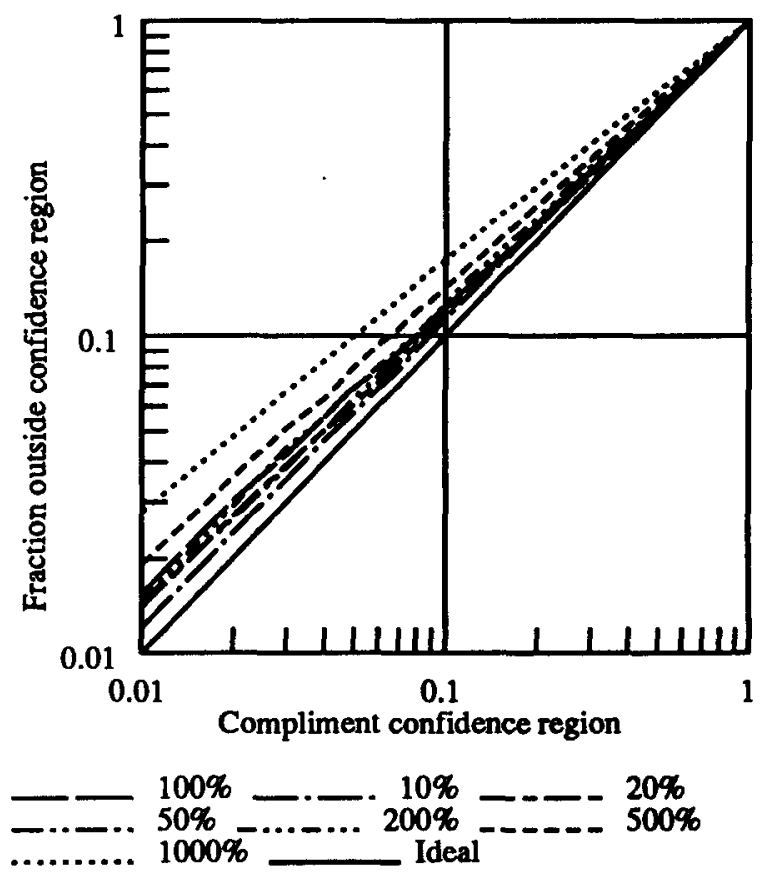

Figure 3: Cumulative likelihood ratio distribution for the Langlie test. 

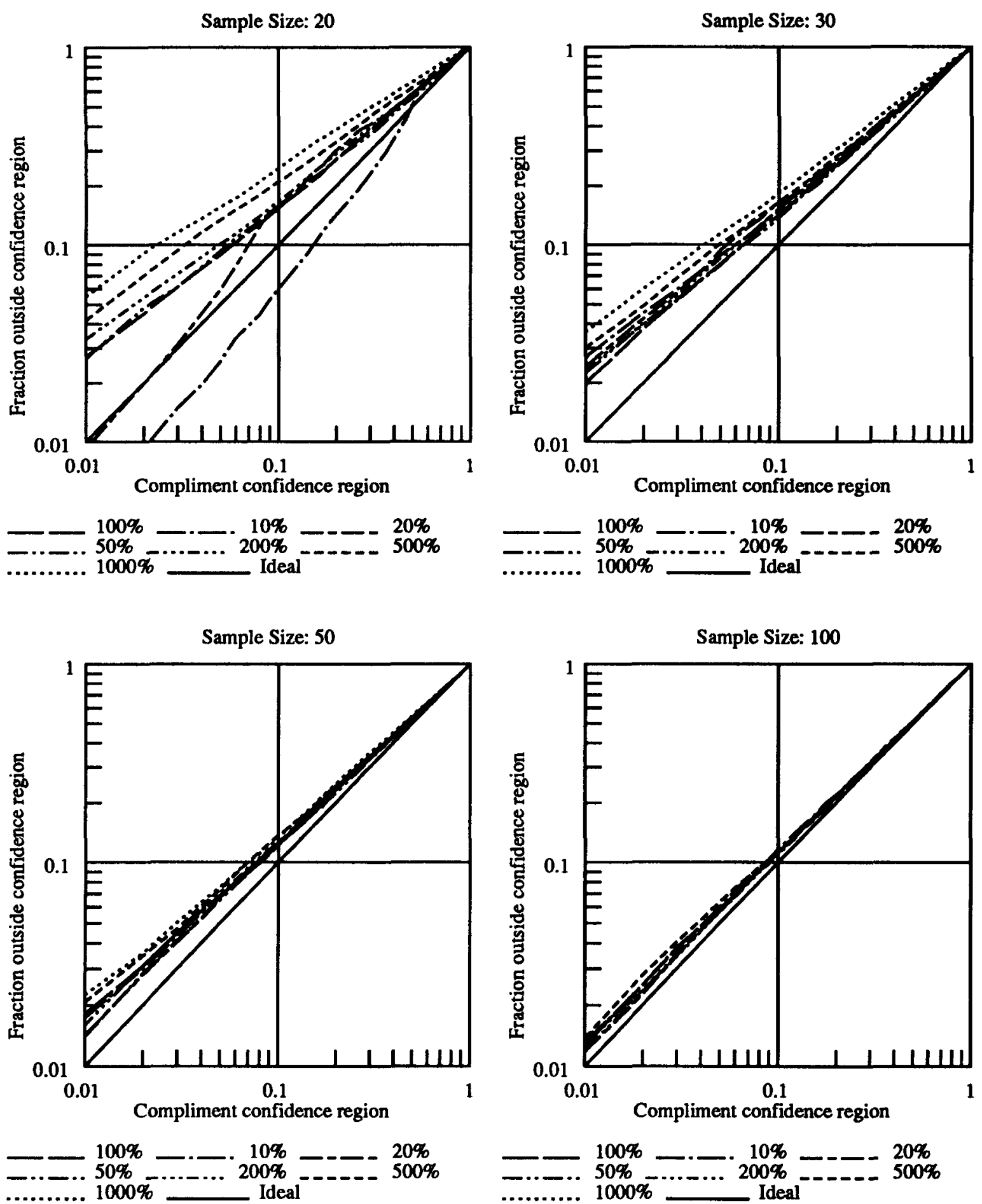

Figure 4: Cumulative likelihood ratio distribution for the Neyer test. 


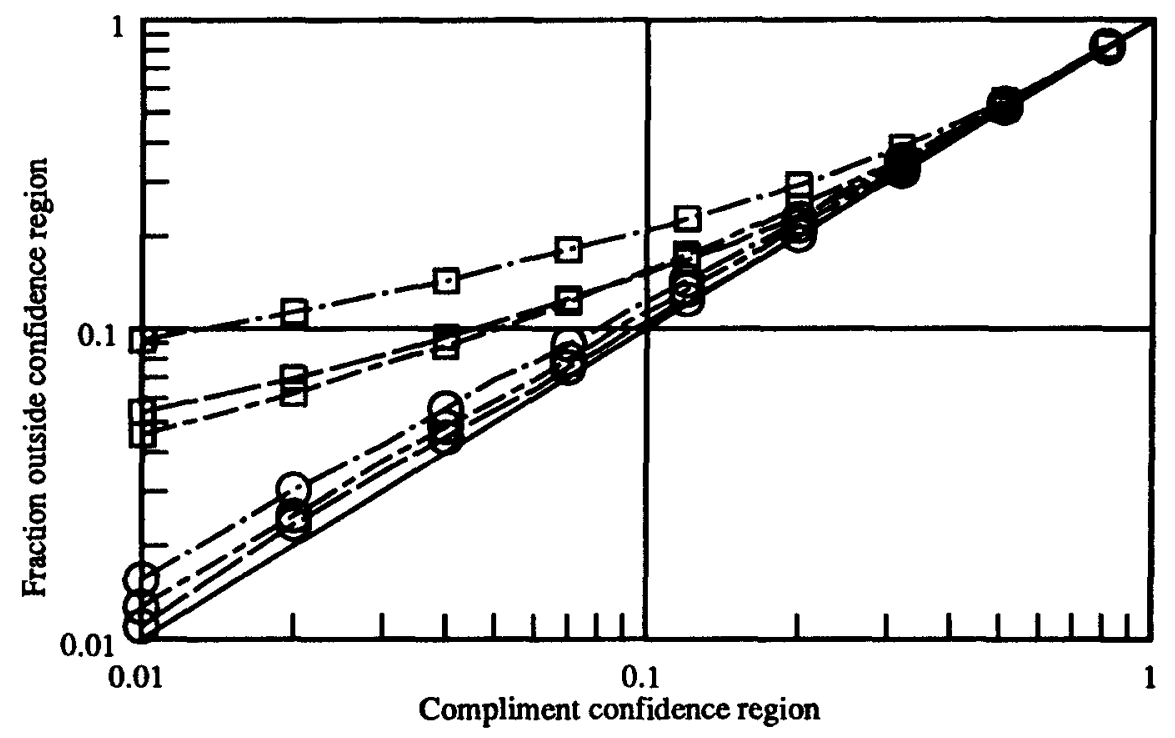

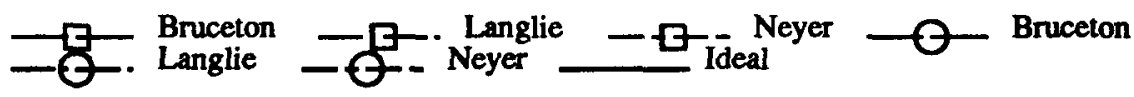

Figure 5: Comparison of asymptotic and Likelihood Ratio Test Confidence Regions. The asymptotic confidence curves are shown with squares and the Likelihood Ratio Test curves are shown with circles. The solid straight line shows the ideal case.

for sample sizes as small as 20 , for efficient tests. Like figures $2-4$, the tests that are inefficient produce ratios further from the asymptotic values, although the deviation is greater for the joint ratios. Thus, the Likelihood Ratio Test can also be used to test whether two samples are from the same population as long as the test is "reasonably efficient." This comparison also has the advantage that it can be used to compare the results of any two tests, even two with different sample sizes and test methods.

\section{Conclusions}

A new method, based on the Likelihood Ratio Test, is proposed for analyzing sensitivity tests. Simulation shows that it is able to analyze the results of all sensitivity tests, including degenerate results, that it produces relatively unbiased analysis, and that the results are valid regardless of the test design. All three of these characteristics are advantages over the currently used asymptotic methods. It is able to analyze single tests to produce confidence regions of various size. It is also able to determine whether two samples were drawn from the same or different populations. The only apparent disadvantage of this test is the significant amount of computation necessary for computing confidence regions. However, these computations can be performed on even small computers in a few seconds or less. 

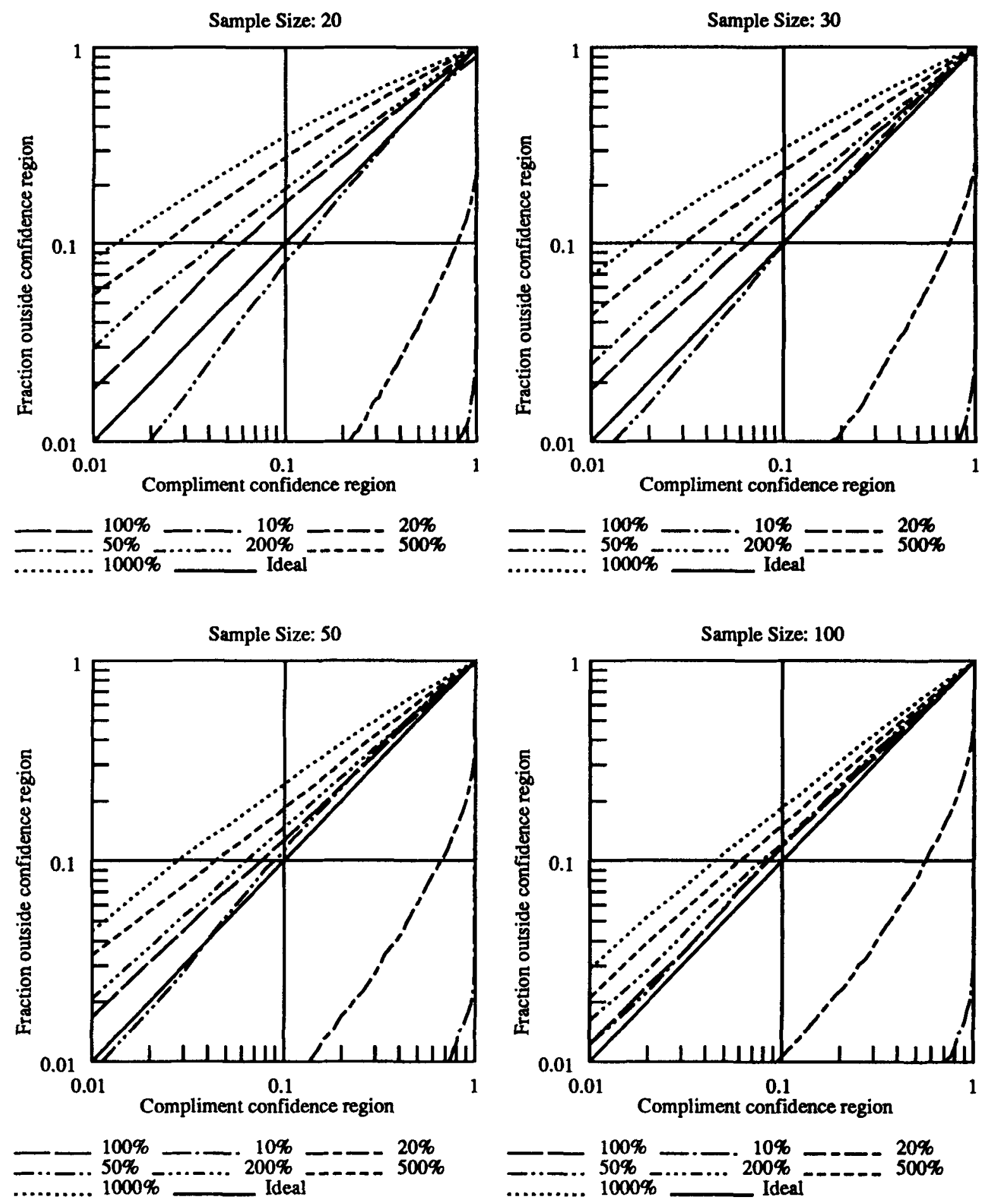

Figure 6: Cumulative dual likelihood ratio distribution for the Bruceton test. 

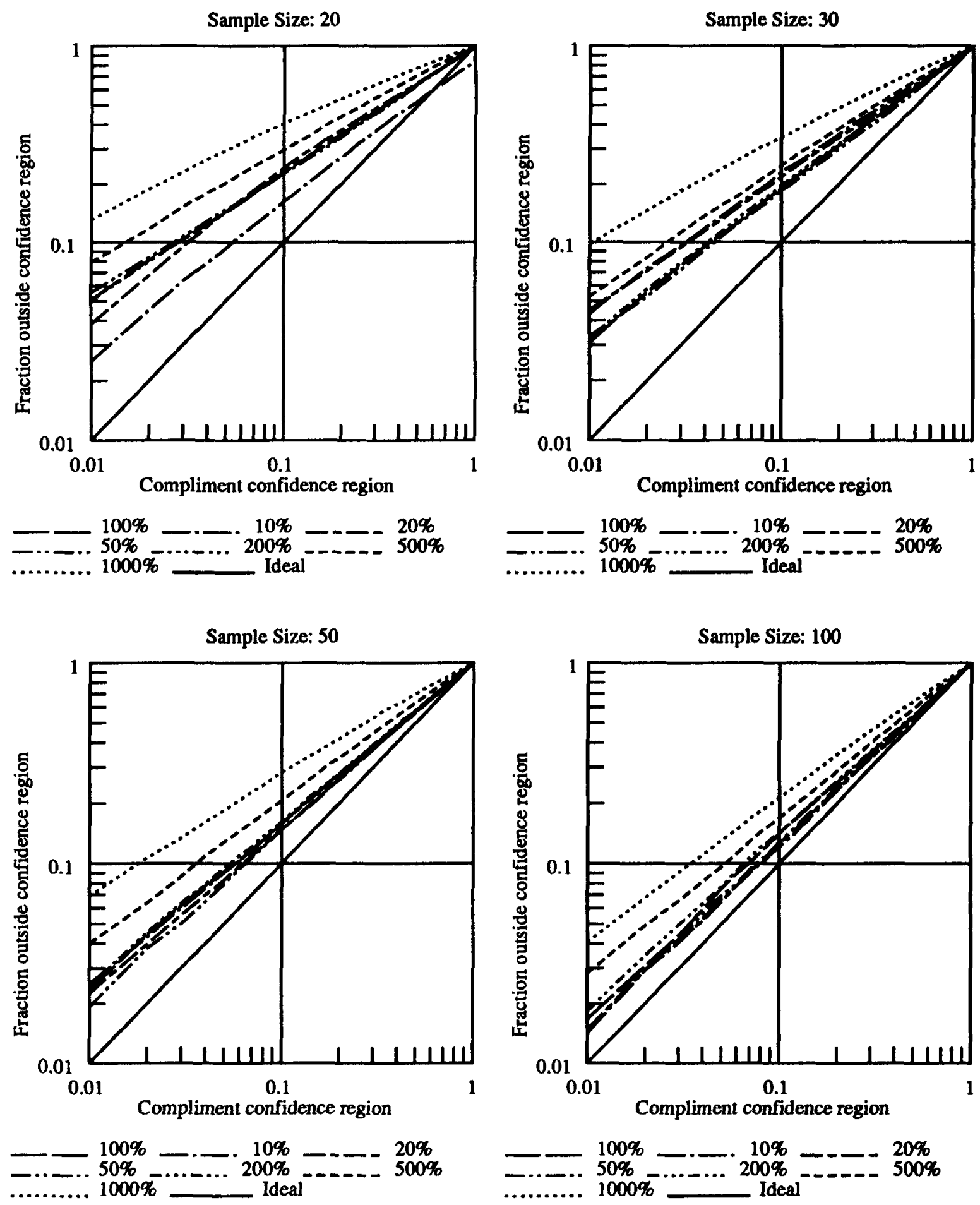

Figure 7: Cumulative dual likelihood ratio distribution for the Langlie test. 
Sample Size: 20
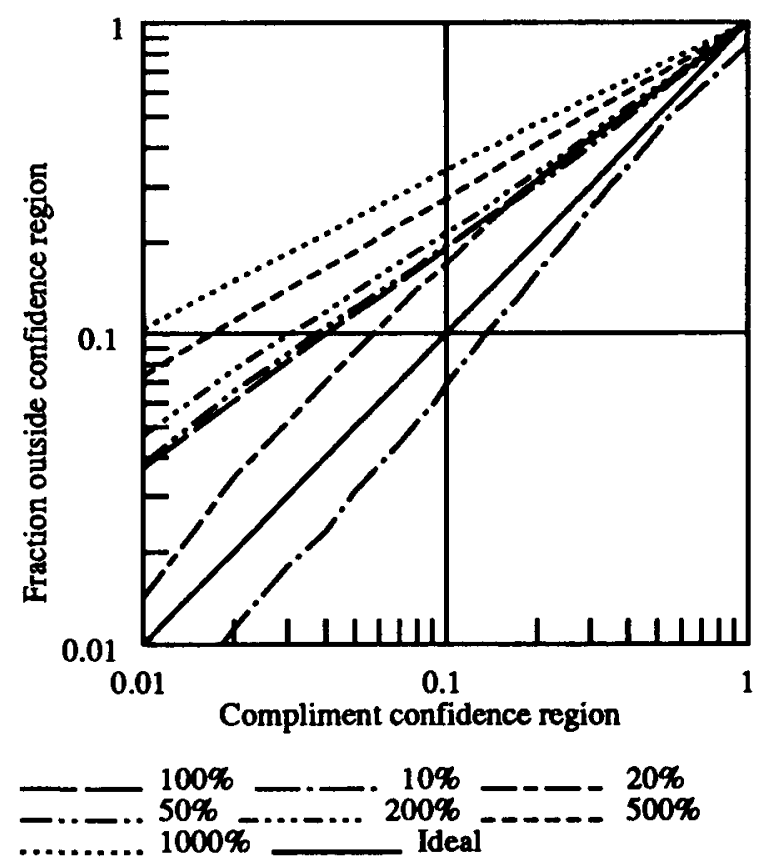

Sample Size: $\mathbf{5 0}$

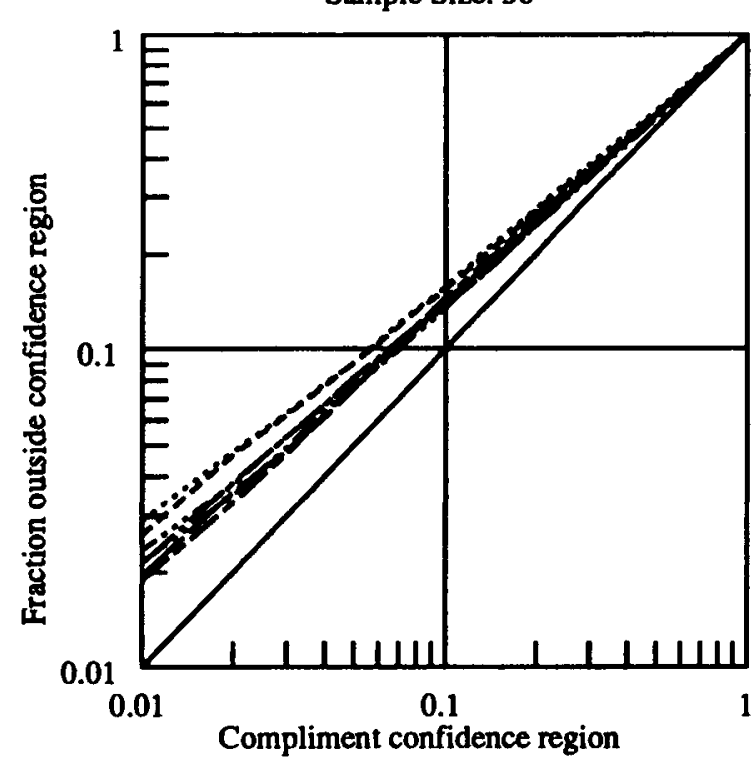

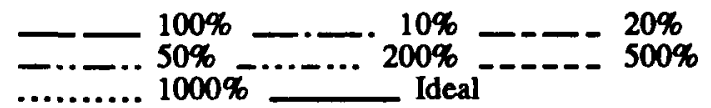

Sample Size: 30
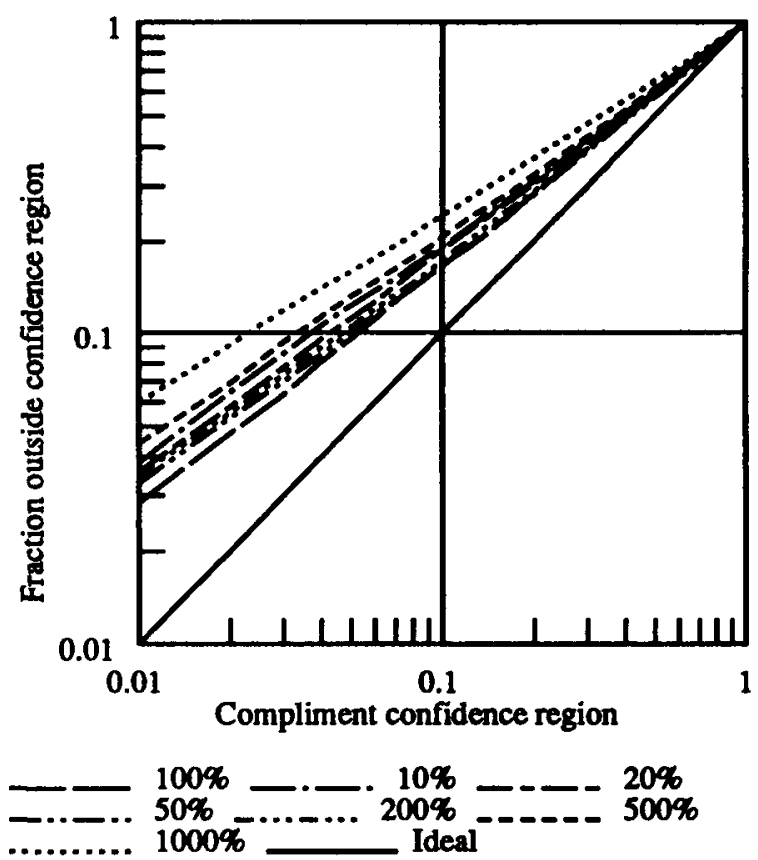

Sample Size: 100

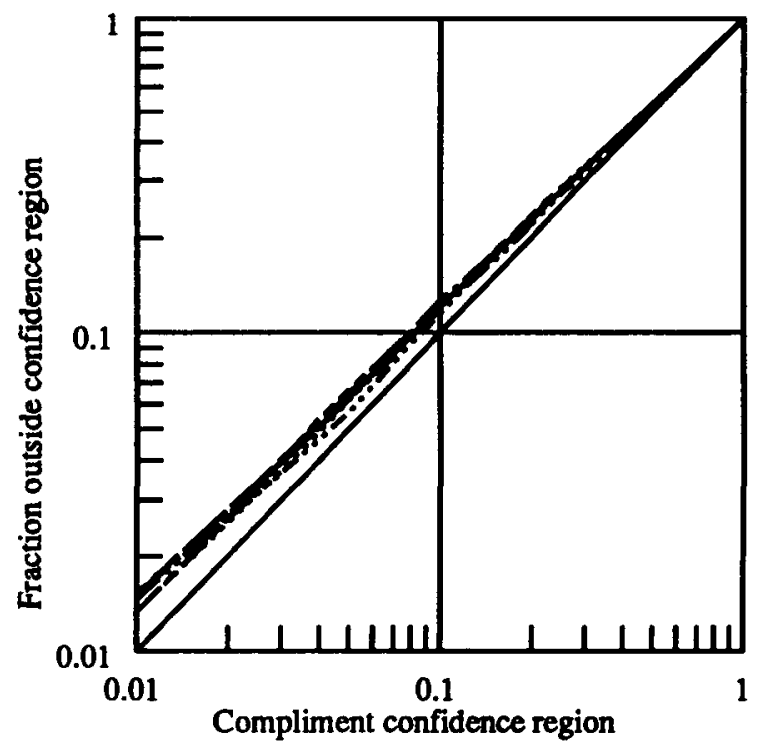

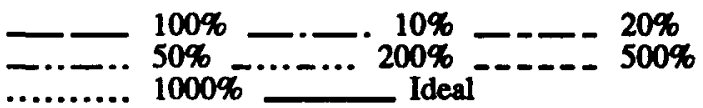

Figure 8: Cumulative dual likelihood ratio distribution for the Neyer test. 


\section{References}

[1] Barry T. Neyer, More Efficient Sensitivity Testing, MLM-3609, EG\&G Mound Applied Technologies, Miamisburg, Ohio (October 1989).

[2] Mervyn J. Silvapulle, "On the existance of maximum likelihood estimators for the binomial response models," Journal of the Royal Statistical Society B, 43 (1981), pp. 310-313.

[3] D. A. Edelman and R. R. Prairie, A Monte Carlo Evaluation of the Bruceton, Probit, and One-Shot Methods of Sensitivity Testing, SC-RR-66-59, Sandia Corporation, Albuquerque, New Mexico (March 1966).

[4] Ramie H. Thompson and James G. Stuart, An Evaluation of Statistical Techniques used in Electroexplosive Device Testing, F-C5867-003, Franklin Research Center, Philidelphia, Pennsylvania (July 1984).

[5] D. J. Finney, Probit Analysis, A Statistical Treatment of the Sigmoid Response Curve. Cambridge at the University Press, Cambridge, England (1947).

[6] J. W. Dixon and A. M. Mood, "A method for obtaining and analyzing sensitivity data," Journal of the American Statistical Association, 43 (1948), pp. 109-126.

[7] H. J. Langlie, A Reliability Test Method For "One-Shot" Items, U-1792, Aeronutronic Division of Ford Motor Company, Newport Beach, California (June 1965).

[8] ONE_SHOT PAC Users Manual, CMOS Records, Balboa, California (1988).

[9] L1SHOT, Franklin Research Institute, Philadelphia Pennsylvania (1987).

[10] ONE_SHOT PAC, Version 1.2, CMOS Records, Balboa, California (1988).

[11] BRUCETON, Franklin Research Institute, Philadelphia Pennsylvania (1989).

[12] B. E. Mills, Sensitivity Experiments: A One-Shot Experimental Design and the ASENT Computer Program, SAND80-8216, Sandia Laboratories, Albuquerque, New Mexico (August 1980).

[13] Maurice G. Kendall and Alan Stuart, The Advanced Theory of Statistics, volume 2. Hafner Publishing Company, New York, second edition (1967).

[14] Robert W. Ashcroft, A Desktop Computer Version of ASENT, MHSMP-81-46, Mason and Hanger, Silas Mason Company, Amarillo, Texas (November 1981).

[15] Robert W. Ashcroft, An IBM PC Version of ASENT, MHSMP-87-51, Mason and Hanger, Silas Mason Company, Amarillo, Texas (December 1987).

[16] LOGIT, Naval Surface Warefare Center, White Oak Maryland (1989).

[17] ASENT, Version 2.1, Barry Neyer Software, Cincinnati, Ohio (1990). 
[18] MUSIG, Version 1.0, National Energy Software Center, Argon, Illinois (1989).

[19] MuSig, Version 2.1, Barry Neyer Software, Cincinnati, Ohio (1989).

[20] ProbPlot, Version 2.1, Barry Neyer Software, Cincinnati, Ohio (1989).

[21] COMSEN, Version 1.0, National Energy Software Center, Argon, Illinois (1989).

[22] ComSen, Version 2.1, Barry Neyer Software, Cincinnati, Ohio (1989). 


\section{Distribution}

\section{EXTERNAL}

OSTI, UC-705 (101)

M. Avory, Quantik Industries

T. Axion, Technology Development Inc.

T. S. Bajpayee, Pittsburg Research Center, U.S. Bureau of Mines

B. Biggs, Motorolla

D. W. Ewick, Ensign Bickford Aerospace

C. Giese, KDI Precision Products

C. Janow, U.S. Army, PM Fuses

R. Johnson, Electronics Development Corp

B. Kremp, Martin Marietta

H. J. Langlie, CMOS Records

J. A. Morley, DOE/DAO

M. Pesko, Stresau Laboratory

L. Richards, Ensign Bickford Aerospace

A. Savarese, U.S. Army, ARDEC

T. Stevens, Electrodynamics

B. Winfield, Unidynamics

R. H. Thompson, Applied Physics Laboratory, Franklin Research Center

J. Yemola, $\mathrm{ICl}$ Americas Inc.

L. Young, Biometry Dept., University of Nebraska, Lincoln

\section{Los Alamos National Laboratory}
R. J. Beckman
E. C. Martinez
G. A. Buntain
J. McAfee
B. P. Ginsburg
D. L. Paisley
W. F. Hemsing
R. H. Warnes
T. E. Larson
R. J. Yactor
J. E. Kennedy

\section{Lawrence Livermere National Laboratory}
G. H. Bloom
R. E. Le日
R. E. Boberg
R. S. Lee
H. H. Chau
C. F. McMillan
J. Cutting
N. A. Schneider
M. Finger
R. A. Van Klompenberg
A. M. Frank
W. G. Von Holle
R. E. Glaser 
Sandia National Laboratory
W. J. Andrzejewski
N. A. Evans
K. G. Pierce
S. G. Barnhart
I. J. Hall
D. R. Begeal
J. G. Harlan
A. M. Renlund
R. W. Bickes
D. Ingersoll
S. Rohde
L. L. Bonzon
R. G. Jungst
P. L. Stanton
F. H. Braaten
V. M. Loyola
W. W. Tarbell
O. L. Burchett
T. M. Massis
W. M. Trott
P. W. Cooper
D. E. Mitchell
M. G. Vigil
K. V. Diegert
L. M. Moore
R. R. Weinmaster
R. G. Easterling
R. $\mathrm{Ng}$
L. J. Weirick
P. D. Wilcox

Armament Lab/Ealin AFATL/MNE
S. A. Aubert
W. Gilliand
L. G. Burdge
D. Hayden
R. C. Erhart
D. Mabry
D. Finella
S. Smith

\section{AFWL/NTED}

G. Goodfellow

J. D. Renrick

\section{Harry Diamond Laboratories}

L. Cox

D. W. Hunter

B. Mary

D. L. Overman

K. Warner

MICOM

B. Betts

J. A. Lineau

\section{NAYSWC/DL}

B. Dibble

W. Elliot

G. Monteith 

J. Bagnall
G. R. Laib
M. C. Beyard
A. Munach
C. S. Coffey
T. Nguyen
B. L. Hanna
M. E. Sitzman
J. F. Jeroski
P. Spann
R. Jones
T. Spivak
B. L. Kuester

\section{NWC/CL}
M. L. Chan
G. N. Hennings
R. D. Cope
W. Maurer
S. Greenum
H. P. Richter
D. Hollingsworth
S. Rohde

\section{Pantex}
R. W. Ashcraft
K. Kuhrts
B. Slape

\section{INTERNAL}

J. L. Allison

M. E. Babcock

P. S. Back

J. A. Bailey

G. L. Ball

T. M. Bruggeman

R. J. Bruns

D. A. Buckner

R. S. Carlson

R. D. Chech

J. C. Cheng

T. S. Chou

R. C. Crosby

T. A. Demana

D. R. Diemunsch

R. J. DeSando

L. J. DeVore

J. V. Dicharo

T. A. Donaldson

L. R. Dosser

E. E. Egleston

W. R. Feairheller

D. W. Firsich

R. A. Fischbein

M. A. Fisher
P. D. Grey

D. J. Gorman

L. D. Haws

J. J. Heinrichs

J. M. Hobbs

M. J. Holt

J. A. Holy

D. A. Homan

G. L. Houston

D. P. Kelley

M. D. Kelly

J. A. Kronenberger

J. W. Leffingwell

D. A. Lentz

J. A. Massie

J. R. McDougal

D. E. Michel

G. D. Miller

J. H. Mohler

A. C. Munger

G. V. Nesslage

B. T. Neyer

D. A. Pawlak

T. D. Peeples

J. M. Pickard
J. W. Pitchford

J. W. Reed

V. E. Robbins

H. L. Robinson

M. A. Robinson

B. D. Rogers

S. C. Rowley

D. R. Schaeffer

W. R. Schurman

M. D. Stoltz

J. S. Sukola

J. A. Thomes

R. Thorpe

E. E. Tibbitts

R. E. Vallee

M. D. Vannet

D. W. Werkmeister

M. K. Williams

V. P. Wilson

C. M. Woods

G. W. Wooten

W. Yurkowsky

Library

Publications

Document Control 